\title{
PLANT REGENERATION FROM MATURE EMBRYO DERIVED CALLUS OF BASMATI RICE
}

\author{
M. S. Ferdous*, M. A. Samad ${ }^{1}$, M. S. Haque and S. A. Mony \\ Department of Biotechnology, Bangladesh Agricultural University \\ Mymensingh-2202, Bangladesh
}

\begin{abstract}
The experiment was conducted with mature embryos of an aromatic rice variety (Basmati 370) to investigate the appropriate growth condition for callus induction as well as plant regeneration. Different concentrations of 2,4-D (0.0, 1.5, 2.5, 3.5, $\left.4.5 \mathrm{mgL}^{-1}\right)$ in MS medium were used for callus induction. Among the concentrations of $2,4-\mathrm{D}, 2.5 \mathrm{mgL}^{-1}$ was the best concentration for callus induction (95.83\%). Different concentrations of Kinetin (0.0, 8.0, 10.0, 12.0, 14.0 $\left.\mathrm{mgL}^{-1}\right)$ with a constant concentration of NAA $\left(0.5 \mathrm{mgL}^{-1}\right)$ were used for plant regeneration from callus. The combination of $10.0 \mathrm{mgL}^{-1}$ Kinetin and $0.5 \mathrm{mgL}^{-1} \mathrm{NAA}$ was found to be the best for shoot regeneration (77.50\%). Different concentrations of MET $\left(1.5,2.5,3.5 \mathrm{mgL}^{-1}\right)$ in MS medium with a constant concentration of NAA $\left(0.5 \mathrm{mgL}^{-1}\right)$ were used for root induction. A combination of $2.5 \mathrm{mgL}^{-1} \mathrm{MET}$ and $0.5 \mathrm{mgL}^{-1} \mathrm{NAA}$ was found most efficient for root induction $(85.00 \%)$ with higher number of roots per plant (19.50) and better root elongation $(1.88 \mathrm{~cm})$. The plantlet was survived well in the plastic pot as well in the earthen pot or in the field.
\end{abstract}

Key words : Rice, Plant regeneration, Mature embryo, Callus induction

\section{INTRODUCTION}

Rice (Oryza sativa L.) a member of the family Graminae and subfamily Oryzoidea, is one of the three leading crops in the world and has a variety of uses. It is the staple food for more than two fifths of the world's population (Latha et al., 2004). At present, genus Oryza consists of two cultivated species and twenty-one wild species. Cultivated rice (Oryza sativa L.) is divided into three subspecies namely indica, japonica and javanica (Datta et al., 2003). It is a major source of food for more than 2.7 billion people on a daily basis and is planted on about one-tenth of the earth's arable land (El-Refaee et al., 2006). Bangladesh is the fourth largest producer and consumer of rice. The crop production in Bangladesh is dominated by intensive rice cropping covering about $77 \%$ of total cropped area around 13.9 million hectares. The demand for special purpose aromatic rice has dramatically increased over the past two decades in the world market (USDA, 2004). Aroma in scented rice has its unique value, from both consumption and commercial point

\footnotetext{
*samad_binapbd@yahoo.com

1 Plant Breeding Division, Bangladesh Institute of Nuclear Agriculture, Mymensingh-2200, Bangladesh
} 
of view. All classes of people consume aromatic rice mostly during social and religious festivals.

Plant Biotechnology, a modern technique is primarily rooted on plant cell culture. Plant tissue culture is the one being applied in crop improvement program. In certain situations, tissue culture techniques are indispensable to achieve the objectives, which are not possible through the conventional methods. Many workers have regenerated complete rice plants from calli derived embryos, anthers, shoot and root as explants. Some of the regenerated plants showed somaclonal variability in $R_{1}$ generation (Lutts et al., 2001).

Plant cell culture techniques have been employed in aromatic rice improvement and varieties development ( $\mathrm{Lim}$ et al. 1998). Tissue culture system was also used to develop highly nutritious and aroma brown Hassawi rice in Saudi Arab (Al-Khayri and AlBahrany, 2000). Inspite of good progress in other countries of the world, little attention has been paid in Bangladesh. The present research work had been planned and carried out to develop to observe the effect of different concentrations of hormone on callus induction and plant regeneration and to develop a suitable and reproducible protocol for in vitro plant regeneration using embryogenic calli from mature embryos of an aromatic rice.

\section{MATERIALS AND METHODS}

The experiment was conducted during the period from January to November 2007 at the Tissue Culture Laboratory of Plant Breeding Division, Bangladesh Institute of Nuclear Agriculture (BINA), Mymensingh. Mature embryos of aromatic rice (Oryza sativa L.) Basmati 370 variety was used as experimental materials in the present investigations. For surface sterilization, the dehusked seeds were taken into a sterilized tube and immersed into $0.1 \% \mathrm{HgCl}_{2}$ solution for 20 minutes followed by $4-5$ rinses with sterile distilled water to remove traces of $\mathrm{HgCl}_{2}$. Mature embryos attached to endosperm were the explants for embryo culture. The explants were cultured directly in MS (Murashige and Skoog, 1962) medium supplemented with different combinations of hormones. MS medium supplemented with 0.0, 1.5, 2.5, 3.5 and $4.5 \mathrm{mgL}^{-1} 2$, 4-D were used for callus induction, while for shoot differentiation MS medium was supplemented with 8.0, 10.0, 12.0 and $14.0 \mathrm{mgL}^{-1} \mathrm{Kn}$ with a constant addition of $0.5 \mathrm{mgL}^{-1} \mathrm{NAA}$ and for root induction MS medium supplemented with 1.5, 2.5 and $3.5 \mathrm{mgL}^{-1}$ MET with a constant concentration of $0.5 \mathrm{mgL}^{-1} \mathrm{NAA}$ were used.

After 7 days of incubation the explants started to produce callus. Then the calli of convenient sizes were placed on a sterilized petridish and were cut into small pieces. They were then sub-cultured to a freshly prepared MS medium for the maintenance of calli without root shoot differentiation. The calli were irradiated and then the irradiated calli were transferred to freshly prepared MS medium containing different hormonal combination for shoot differentiation. Some of the subcultured calli continued to proliferate and differentiate into shoots. When shoots 
grew to about 3-6 cm in height, these were separated aseptically from each other and transferred to freshly prepared rooting medium.

Sterilized potting mixture containing garden soil, sand and cowdung in the ratio of 1:2:1 was taken into $10 \mathrm{~cm}$ plastic pots for growing the plantlets at in vivo condition. The regenerated plantlets with sufficient roots were then taken out from the culture vessels and thoroughly washed in running tap water to remove all adherent culture medium. The plantlets were then transplanted to small pots containing potting mixture. The pots with the plantlets were covered immediately with polythene bags to prevent excessive evapotranspiration. The pots were kept in the controlled environment of glass house to reduce shock. After 10-15 days, the plantlets were transferred to the field where they developed into mature plants.

Data recorded for different parameters under study were compiled and tabulated for statistical analysis. The experiment was arranged in Completely Randomized Design (CRD) and the data were analyzed using statistical package MSTAT-C software developed by Russel (1986). The analysis of variance (ANOVA) for different characters was performed and the mean values were compared by the Duncan's Multiple Range Test (DMRT).

\section{RESULTS AND DISCUSSION}

In the present investigation, a technique for plantlet regeneration in vitro through callus induction, shoot regeneration and rooting of the shoots has been established by using mature embryos of aromatic rice genotype namely Basmati 370 as explants. The explants were inoculated on MS medium supplement with different concentrations of 2,4$\mathrm{D}$ for the callus formation (Fig. 1A). In medium without growth regulator, no callus was induced. The highest percentage $(95.83 \%)$ of explants showed callus induction in $2.5 \mathrm{mgL}^{-1} 2,4-\mathrm{D}$ followed by $1.5 \mathrm{mgL}^{-1} 2,4-\mathrm{D}(79.16 \%)$ and the lowest percentage $(50.00 \%)$ of callus induction was found in $4.5 \mathrm{mgL}^{-1} 2,4-\mathrm{D}$ (Table1).

Table 1. Effect of different concentrations of 2,4-D in MS medium on callus induction

\begin{tabular}{|c|c|c|}
\hline Effects & $\%$ of callus induction & Days required for callus induction \\
\hline \multicolumn{3}{|l|}{$2,4-\mathrm{D}\left(\mathrm{mgL}^{-1}\right)$} \\
\hline 0.0 & $0.00 \mathrm{e}$ & $0.00 \mathrm{~d}$ \\
\hline 1.5 & $79.16 b$ & $8.25 b$ \\
\hline 2.5 & $95.83 a$ & $7.50 \mathrm{c}$ \\
\hline 3.5 & $62.49 c$ & $9.25 a$ \\
\hline 4.5 & $50.00 \mathrm{~d}$ & $9.75 a$ \\
\hline
\end{tabular}

Figures followed by the same letters in a column do not differ, significantly at $5 \%$ level of significance as DMRT 
In most of the early reports, $2.5 \mathrm{mgL}^{-1} 2,4-\mathrm{D}$ was found to be the best for callus induction (Al-Khyri and Al-Bahrany, 2000). This concentration emerged as the optimum concentration 2,4-D for callus formation in our study and can be considered as most suitable for callus formation in rice irrespective of genotype. Maintenance of calli for long period is highly necessary to study the callus proliferation and subsequent plantlet regeneration. Thus, calli raised from different explants were successfully sub-cultured them at the interval of 15 days in MS medium supplemented with different concentrations of 2,4-D $(0,1.5,2.5$, 3.5, $4.5 \mathrm{mgL}^{-1}$ ) (Fig. 1B).

Different combinations of NAA and Kinetin was highly significant for per cent explants showing shoot regeneration indicating that there were significant differences among the concentration levels. The highest percentage of explants showing shoot regeneration was found in $0.5 \mathrm{mgL}^{-1} \mathrm{NAA}$ and $10.0 \mathrm{mgL}^{-1}$ Kinetin $(77.50 \%)$ and the lowest percentage of explants showing shoot regeneration was found with $0.5 \mathrm{mgL}^{-1} \mathrm{NAA}$ and $14.0 \mathrm{mgL}^{-1}$ Kinetin $(55.00 \%)$. The highest shoot length $(5.83 \mathrm{~cm})$ was also found in $0.5 \mathrm{mgL}^{-1} \mathrm{NAA}$ and $10.0 \mathrm{mgL}^{-1}$ Kinetin concentrations and the lowest shoot length was recorded in $0.5 \mathrm{mgL}^{-1} \mathrm{NAA}$ and $14.0 \mathrm{mgL}^{-1}$ Kinetin $(5.45 \mathrm{~cm})$ (Table 2$)$.

Table 2. Effect of different concentrations of Kinetin in presence of $0.5 \mathrm{mgL}^{-1} \mathrm{NAA}$ on plant regeneration

\begin{tabular}{l|c|c}
\hline \multicolumn{1}{c|}{ Effects } & \% of shoot induction & Shoot length $(\mathrm{cm})$ \\
\hline Kinetin $\left(\mathrm{mgL}^{-1}\right)$ & & \\
\hline 0 & $0.00 \mathrm{e}$ & $0.00 \mathrm{e}$ \\
8 & $72.50 \mathrm{~b}$ & $5.75 \mathrm{~b}$ \\
10 & $77.50 \mathrm{a}$ & $5.83 \mathrm{a}$ \\
12 & $57.50 \mathrm{c}$ & $5.55 \mathrm{c}$ \\
14 & $55.00 \mathrm{~d}$ & $5.45 \mathrm{~d}$ \\
\hline
\end{tabular}

Figures followed by the same letters in a column do not differ, significantly at $5 \%$ level of significance as DMRT

MS medium supplemented with different concentrations of MET (1.5, 2.5 and 3.5 $\left.\mathrm{mgL}^{-1}\right)$ with a fixed concentration $\left(0.5 \mathrm{mgL}^{-1}\right)$ of NAA were used to evaluate the performance of aromatic rice genotype. Among the treatments, $\mathrm{T}_{2}\left(\mathrm{MS}+0.5 \mathrm{mgL}^{-1}\right.$ $\mathrm{NAA}+2.5 \mathrm{mgL}^{-1} \mathrm{MET}$ ) proved to be the most effective root inducing media than the other treatments $\left(\mathrm{T}_{1}\right.$ and $\left.\mathrm{T}_{3}\right)$. The highest number of root per plant was also recorded at $2.5 \mathrm{mgL}^{-1}$ MET level (19.50) and the lowest number of root per plant was recorded at 3.5 $\mathrm{mgL}^{-1}$ MET level (16.50) and the highest length of root was recorded at $2.5 \mathrm{mgL}^{-1} \mathrm{MET}$ level $(1.88 \mathrm{~cm})$ and the lowest length of root was recorded at $3.5 \mathrm{mgL}^{-1}$ MET level $(1.55$ $\mathrm{cm})$ (Table 3). 
The present results were supported by the findings of Islam (2004) who observed the effect of MET (2.5 mgL-1) and NAA $\left(0.5 \mathrm{mgL}^{-1}\right)$ on root formation in indica rice (Oryza sativa L. cv. Kataribhogs) and reported that maximum root induction was occurred from this hormonal combination.

Table 3. Effect of different concentrations of MET in presence of $0.5 \mathrm{mgL}^{-1} \mathrm{NAA}$ on root induction

\begin{tabular}{l|c|c|c}
\hline \multicolumn{1}{c|}{ Effects } & \% of root induction & Number of root plant ${ }^{-1}$ & Root length $(\mathrm{cm})$ \\
\hline \multicolumn{4}{l}{ MET $\left(\mathrm{mgL}^{-1}\right)$} \\
\hline 1.5 & $67.50 \mathrm{~b}$ & $17.50 \mathrm{~b}$ & $1.68 \mathrm{~b}$ \\
2.5 & $85.00 \mathrm{a}$ & $19.50 \mathrm{a}$ & $1.88 \mathrm{a}$ \\
3.5 & $62.50 \mathrm{c}$ & $16.50 \mathrm{c}$ & $1.55 \mathrm{c}$ \\
\hline
\end{tabular}

Figures followed by the same letters in a column do not differ, significantly at $5 \%$ level of significance as DMRT
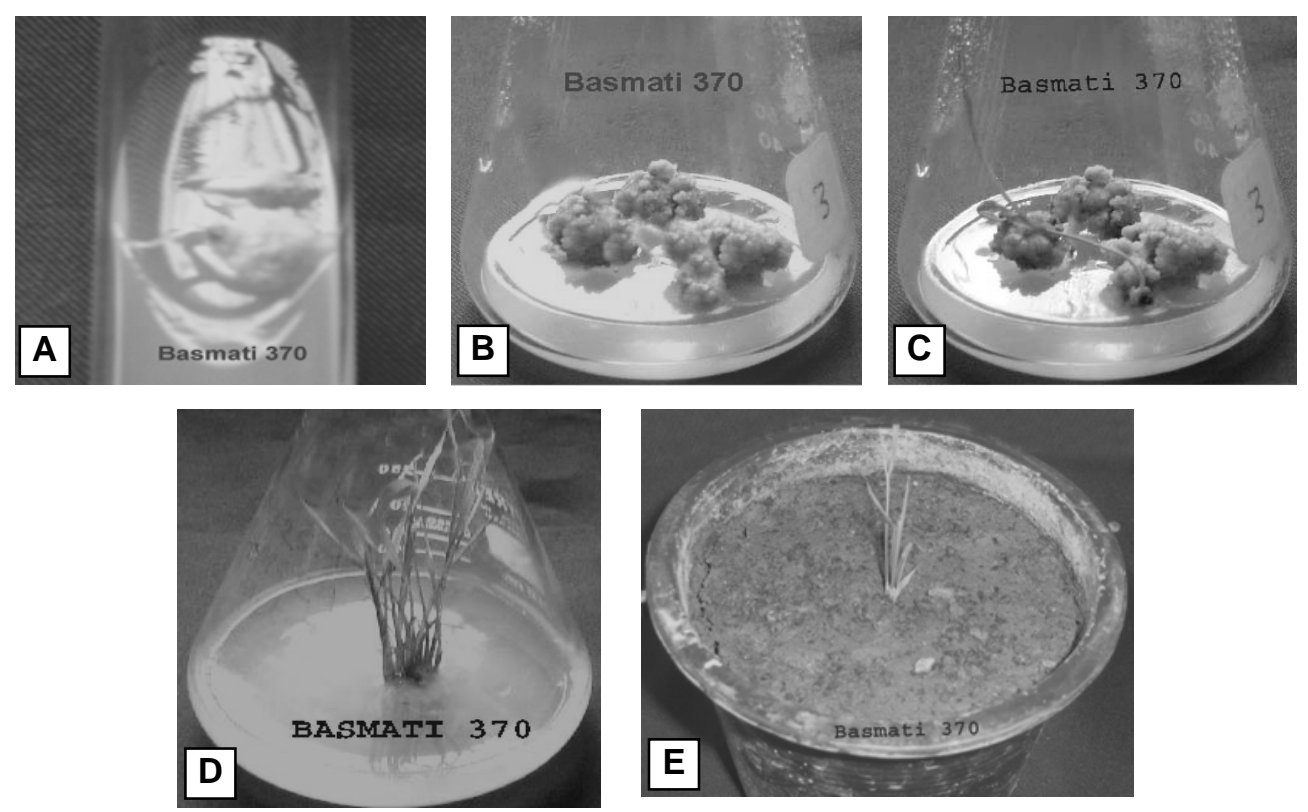

Fig. 1. Plant regeneration of aromatic rice : (A). Callus induction from mature embryos of aromatic rice genotype in MS medium supplemented with 2.5 $\mathrm{mgL}^{-1} 2,4-\mathrm{D}$ in light condition (21 days after inoculation). (B). Maintenance of embryo derived callus with $2.5 \mathrm{mgL}^{-1} 2,4-\mathrm{D}$ (10 days after inoculation). (C). Shoot regeneration from embryo derived callus with $0.5 \mathrm{mgL}^{-1} \mathrm{NAA}$ and $10.0 \mathrm{mgL}^{-1}$ Kinetin (30 days of implanting). (D). Rooted plantlets of aromatic rice on MS medium supplemented with $0.5 \mathrm{mgL}^{-1} \mathrm{NAA}+2.5$ $\mathrm{mgL}^{-1}$ MET (15 days of implanting). (E). Acclimatized plantlets of aromatic rice variety Basmati 370 in plastic pot. 
The small plantlets, after sufficient development in root system, were taken out from the culture vessels without causing any damage to roots. Excess media adhered around the roots was washed off by running tap water to prevent microbial infection. Then the plantlets were transplanted into small plastic pots containing sterile soil, sand and cowdung in a 1:2:1 ratio. The pots were covered with clear polybag to maintain high humidity conditions and kept in the growth camber for proper hardening (Fig. 1E). Gradually the plantlets were adapted to the soil.

\section{REFERENCES}

Al-Khayri, J. M. and Al-Bahrany, A. M. 2000. In vitro plant regeneration of Hassani Rice from Mature Embryo Callus. Pakistan J. Biol. Sci., 3(4): 602-605.

Datta, K., Baisakh, N., Oliva, N., Torrizo, L., Abrigo, E., Tan, J., Rai, M., Rehana, S., Al-Babill, S., Beyer, P., Potrykus, I. and Datta, S. K. 2003. Bioengineered "golden" indica rice cultivars with $B$ carotene metabolism in the endosperm with hygromycin and mannos selection systems. J. Plant Biotechnol., 1(2): 81.

El-Refaee, Y. Z, Atallah, M., Savo-Sardaro, M. L. and Porceddu, E. 2006. Fine QTLs Mapping For Salinity Tolerance in Rice. Proceedings of the 50th Italian Society of Agricultural Genetics Annual Congress. Ischia, Italy. ISBN 88-900622-7-4.

Islam, M. M. 2004. Effect of irradiation on seeds and calli for regeneration of plants from a fine grain rice (Oryza sativa L.) cv. Kataribhog. M. S. Thesis, Dept. Genet. Plant Breed. Bangladesh Agril. Univ., Mymensingh.

Latha, R., Rao, C. S., Subramaniam, H. M. S., Eganathan, P. and Swaminathan, M. S. 2004. Approaches to breeding for salinity tolerance a case study on Proterena coarctata. Ann. Appl. Biol., 144(2): 177-184.

Lim, S. J., Yang, S. J., Song, Y. C., Oh, B. G., Yeo, U. S., Yi, G. H., Nam, M. H., Park, N. B., Hwang, H. G., Kang, J. R., Chang, J. G., Kim, S. C. and Oh, Y. J. 1998. A new aromatic and glutinous japonica rice variety "Aranghyangchalbueo". RDA J. Crop Sci. II., 40(2): 9-15.

Lutts, S., Kinet, J. M. and Bouharmont, J. 2001. Somaclonal variation in rice after two successive cycles of mature embryo derived callus culture in the presence of $\mathrm{NaCl}$. Biol. Plant., 44: 4.

Murashige, T. and Skoog, F. 1962. A revised medium for rapid growth and bioassay with tobacco tissue culture. Physiol. Plant., 15: 473-497.

Russel, D.F. 1986. MSTAT-C. Crop and Soil Sci. Dept., Mitchigan State Univ., USA.

USDA. 2004. Rice Situation and Outlook Yearbook. p. 88. 